\section{Autoantibodies and interstitial lung disease in rheumatoid arthritis: towards a 'mix-and- match' approach?}

We read with interest the article by Castellanos-Moreira et al who identified for the first time an association between anticarbamylated protein antibodies and interstitial lung disease (ILD) in patients with rheumatoid arthritis (RA). ${ }^{1}$ The reported prevalence of ILD in RA ranges from $4 \%$ to $70 \%$ according to different cohorts and inclusion criteria. The clinical spectrum is rather broad ranging from mild reversible lung inflammatory disease to rapidly progressing fibrotic conditions with poor prognosis and frequent cause of death. On this basis, clinicians should be alert and promptly identify, classify and manage ILD according to its features and severity. However, whether a patient with RA will develop or not ILD, depends on several genetic, demographic, environmental and immunological factors that interact with each other and reliable markers able to predict ILD development are currently lacking. ${ }^{2}$ The increasing knowledge on novel autoantibody specificities in RA could allow a better understanding of immunological mechanisms underlying different disease features ${ }^{3}$ and, in this regard, the study by CastellanosMoreira is of great relevance. However, some aspects need to be remarked. They observed an association of ILD and antibodies against two carbamylated antigens (fetal calf serum (FCS) and chimeric fibrin/filaggrin homocitrullinated peptide (CFFHP) in a regression model adjusted for age, disease duration, anticitrullinated proteins antibodies (ACPA), rheumatoid factor, sex and smoking cumulative dose. The population of patients was mainly constituted by females (79\%) seropositive for ACPA (72\%). What remains unclear, however, are the striking differences with the replication cohort with an OR almost three fold higher for anti-FCS and a lack of significant association between ILD and anti-CFFHP. It is interesting to note that gender distribution in the replication cohort is significantly different compared with the main cohort, with males being equally represented than females (F/M replication cohort 40/35, main cohort 141/38; $\left.\chi^{2} \mathrm{p}<0.0001\right)$. In addition, the cumulative smoking dose in the replication cohort is similar in patients with or without ILD, although a surprising trend towards higher values in non-ILD patients is observed. Conversely, in the main cohort, patients with ILD have a significantly higher smoking cumulative dose compared with those without ILD. As far as serology is concerned, differences can be seen between the two cohorts, with a higher prevalence of ACPA in the replication compared with the main one (ACPA+/ACPA - replication cohort 65/10, main cohort $\left.128 / 51 ; \chi^{2} \mathrm{p}=0.01\right)$. Within each cohort, ACPA are equally distributed in patients with or without ILD. It would be interesting to see the individual ORs obtained at univariate analysis before building a model adjusted for the same variables in the two cohorts.

When performing a similar exercise and assessing the relationship between ILD and anticitrullinated alpha enolase peptide- 1 (anti-CEP-1), we enrolled 252 RA patients (77\% females, 66\% anticyclic citrullinated peptide (anti-CCP) positive) and observed that anti-CEP-1 single positivity and anti-CCP/anti-CEP-1 double positivity, but not anti-CCP single positivity, were associated with ILD. ${ }^{4}$ An increasing number of papers is supporting the hypothesis that it is a matter of which autoantibodies test positive and also how many specificities of the same antibody family coexist to be able to predict risk of developing RA, the response to treatment or the development of erosive disease. ${ }^{5-7}$

Such assessment in the cohorts tested by Castellanos-Moreira may help explaining the different results obtained in the two cohorts and ultimately facilitate the design of longitudinal studies aimed at understanding the predictive value of different antibody specificities assessed at the time of RA diagnosis for the future development of ILD. In the era of precision medicine, a mix-and-match approach combining test for antibodies with a diagnostic and/or a prognostic value may be a powerful tool to optimise the tailoring of follow-up and treatment strategies.

\section{Alessia Alunno $\odot$, Onelia Bistoni, Angelo Francesco Bonifacio, Roberto Gerli}

Department of Medicine, Rheumatology Unit, University of Perugia, Perugia, Italy

Correspondence to Roberto Gerli, Department of Medicine, Rheumatology Unit, University of Perugia, Perugia 06129, Italy; roberto.gerli@unipg.it

Contributors All authors drafted and approved the final version of the manuscript.

Funding The authors have not declared a specific grant for this research from any funding agency in the public, commercial or not-for-profit sectors.

Competing interests None declared.

Patient and public involvement Patients and/or the public were not involved in the design, or conduct, or reporting or dissemination plans of this research.

Patient consent for publication Not required.

Provenance and peer review Not commissioned; internally peer reviewed. (C) Author(s) (or their employer(s)) 2020. No commercial re-use. See rights and permissions. Published by BMJ.

$$
\text { Check for updates }
$$

To cite Alunno A, Bistoni O, Bonifacio AF, et al. Ann Rheum Dis Epub ahead of print: [please include Day Month Year]. doi:10.1136/annrheumdis-2020-217410

Received 24 March 2020

Accepted 26 March 2020

Ann Rheum Dis 2020;0:1. doi:10.1136/annrheumdis-2020-217410

\section{ORCID iD}

Alessia Alunno http://orcid.org/0000-0003-1105-5640

\section{REFERENCES}

1 Castellanos-Moreira R, Rodríguez-García SC, Gomara MJ, et al. Anti-carbamylated proteins antibody repertoire in rheumatoid arthritis: evidence of a new autoantibody linked to interstitial lung disease. Ann Rheum Dis 2020. doi:10.1136/ annrheumdis-2019-216709

2 Alunno A, Gerli R, Giacomelli R, et al. Clinical, epidemiological, and histopathological features of respiratory involvement in rheumatoid arthritis. Biomed Res Int 2017;2017:1-8.

3 Bonifacio AF, Alunno A, La Paglia GMC, et al. Novel autoantibodies in rheumatoid arthritis. Reumatismo 2019;71:1-12.

4 Alunno A, Bistoni O, Pratesi F, et al. Anti-citrullinated alpha enolase antibodies, interstitial lung disease and bone erosion in rheumatoid arthritis. Rheumatology 2018:57:850-5.

5 Joshua V, Hensvold A, Reynisdottir G, et al. Number and type of AcpA fine sspecificities are correlated to high resolution computed tomography parenchymal lungs changes in patients with early untreated rheumatoid arthritis. Arthritis Rheumatol 2017;69.

6 Juarez M, Bang H, Hammar F, et al. Identification of novel antiacetylated vimentin antibodies in patients with early inflammatory arthritis. Ann Rheum Dis 2016;75:1099-107

7 Sieghart D, Platzer A, Alasti F, et al. The prognostic value of autoantibody isotypes for predicting therapeutic responses to methotrexate in patients with rheumatoid arthritis. Arthritis Rheumatol 2018;70. 